Revista lus et Praxis, Año 24, No 3, 2018, pp. 173 - 208

ISSN 0717 - 2877

Universidad de Talca - Facultad de Ciencias Jurídicas y Sociales

Negociación colectiva, autonomía y abstención legislativa

Sergio Gamonal Contreras - Pablo Arellano Ortiz

Trabajo recibido el 30 de octubre de 2017 y aprobado el 30 de mayo de 2018

\title{
Negociación colectiva, autonomía y abstención legislativa
}

\author{
Collective BARGAINING, AUTONOMY AND LEGISLATIVE AUTONOMY*
}

\author{
Sergio Gamonal Contreras ${ }^{* *}$ \\ Pablo Arellano Ortiz
}

\section{RESUMEN}

Este artículo estudia dos de los más conocidos sistemas de abstención legislativa en materia sindical. El caso de Uruguay y de Italia, analizando sus caracteres y desafíos principales, para presentar algunas propuestas acerca del modo más adecuado de articulación entre ley y autonomía en el contexto de los sistemas sindicales de América Latina.

\section{ABSTRACT}

This paper studies two of the most well known systems of legislative abstention in freedom of association matters. The case of Uruguay and Italy, analyzing their main characters and challenges, to present some proposals about the most appropriate way of articulating law and autonomy in the context of the Latin American trade union systems.

$$
\text { PaLABRAS CLAVE }
$$

Autonomía, intervención, libertad sindical

KEY WORDS

Autonomy, intervention, freedom of association

\section{Introducción: autonomía e intervención en la negociación colectiva}

El derecho del trabajo se ha desarrollado por medio de dos caminos complementarios. Por un lado, a través de la tutela individual del trabajador considerado como el contratante débil de la relación laboral' ${ }^{1}$, conocido también como la línea

\footnotetext{
* Este artículo forma parte del Proyecto Fondecyt Regular titulado "La negociación colectiva y su ámbito de cobertura más allá de la empresa", № 1170132, en el que el profesor Gamonal es el Investigador Principal.

** Licenciado en Ciencias Jurídicas y Sociales, Universidad de Chile. Profesor de Derecho del Trabajo, Universidad Adolfo Ibáñez, Santiago, Chile (sergio.gamonal@uai.cl).

*** Especialista en Derecho del Trabajo, Unidad de Derecho Laboral y Reforma, Departamento de Gobernanza y Tripartismo de la OIT, Ginebra (Suiza); Investigador, Facultad de Derecho, Pontificia Universidad Católica de Valparaíso (Chile). Las opiniones expresadas incumben solamente al autor y no representan necesariamente los puntos de vista de la Oficina Internacional del Trabajo o de la Organización Internacional del Trabajo (arellano@ilo.org).

1 Gamonal (2013), p. 14.
} 
constitucional del garantismo individual protagonizado por la ley². Y, por otro lado, por medio de la tutela colectiva basada en los sindicatos, la negociación colectiva y la huelga ${ }^{3}$, conocida también como la línea sindicalista del derecho laboral ${ }^{4}$.

En palabras de Américo Plá: "...en todo el derecho del trabajo hay un punto de partida: la unión de los trabajadores, y un punto de llegada: el mejoramiento de las condiciones de los trabajadores. Derecho individual y derecho colectivo del trabajo son simplemente distintas sendas para recorrer el mismo itinerario"s.

La tutela colectiva llegó a su más alta expresión en la segunda mitad del siglo XX y hasta fines de la década de los setenta, evolucionando de forma espectacular en gran parte de Europa y en países de capitalismo avanzado .

La tutela colectiva se encuentra en aquellos sistemas con un movimiento sindical fuerte, capaz de velar por los intereses de sus asociados, así como de los demás trabajadores en el lugar de trabajo y en la categoría profesional, en virtud de la representación de intereses de rango colectivo que realiza. Esta tutela es reconocida como la más completa y perfecta en materia laboral, dado que empodera a los trabajadores equilibrando la relación laboral ${ }^{7}$.

La tutela colectiva o línea sindical ha llegado a constituir un pilar del sistema democrático ${ }^{8}$, presentando un mayor desarrollo en aquellos sistemas de amplia cobertura porque son de negociación ramal o de sector, o porque tienen algún mecanismo de extensión de la negociación. En efecto, en la Unión Europea encontramos distintos sistemas, desde negociación a nivel de empresa (Gran Bretaña y Malta) hasta mecanismos de extensión de los contratos colectivos en casi todos los países de la Unión ${ }^{9}$ y en los 16 países con mayor productividad laboral en la OCDE, en el año 2014, existía negociación colectiva ramal (en algunos es la forma predominante de negociar y en otros está presente sin ser dominante) ${ }^{10}$.

En América Latina la negociación colectiva está centrada en al empresa en casi todos los países (con la excepción de Argentina y Uruguay), y la tasa de cobertura es bastante baja, aunque muchos países tienen extensas y detalladas

\footnotetext{
2 Givgni (1989), p. 333.

3 Véase Gamonal (2011), pp. 9 y ss., y Walker y Arellano (2017), pp. 93 y ss.

4 Giugni (1989), p. 333.

5 PlÁ (1998), p. 44.

6 Gamonal (2013), p. 15.

7 Véase entre otros autores: Kahn-Freund (1987), p. 54; Baylos (1991), p. 39; Supiot (1996), p. 148, y D'ANTONA (2000), pp. 1217 y 1218.

8 Baylos (2012), p. 22.

9 FITA (2014), p. 16.

10 DURÁN (2015).
} 
leyes sobre sindicatos, negociación y huelga ${ }^{11}$. De lo cual se colige que los niveles de cobertura y de extensión de la negociación colectiva son relativamente débiles.

En la búsqueda de una mayor cobertura de la negociación colectiva sin lugar a dudas la negociación ramal aparece como un ideal a seguir. Sin embargo, su establecimiento legislativo queda confrontado a la real capacidad de los sindicatos para poder actuar, proteger y extender beneficios. En este trabajo intentaremos estudiar la relación entre la autonomía y la regulación legislativa, entendiendo que dicha relación posee un impacto en los niveles de cobertura y de extensión de beneficios. De esta manera, nos parece atingente para entender mejor cómo pueden coordinarse la ley y la autonomía colectiva de los sindicatos dentro de un sistema de relaciones laborales el plantarse preguntas tales como, ¿Cómo se coordinan la ley y las fuentes de derecho estatal con la autonomía de los sindicatos? ¿Pueden desarrollarse los sindicatos y la negociación sin el auxilio estatal? ¿Cómo se han desarrollado aquellos sistemas que se caracterizan por un abstencionismo legislativo, entendido como aquellos en que el legislador interviene en forma minimalista en las relaciones sindicales? ${ }^{12}$ En estos sistemas, denominados también como de "laissez-faire colectivo"13, el sistema autónomo de relaciones laborales se basa en el rol protagónico de los actores sociales con relativa independencia del Estado, que se limita a establecer normas mínimas a fin de asegurar ciertos niveles de necesario cumplimiento y evitar excesos o abusos ${ }^{14}$.

Entendemos que estas preguntas resultan de interés frente al sobre reglamentado sistema sindical que suelen tener los países de América Latina ${ }^{15}$, donde el legislador regula casi todos los aspectos del sindicalismo, de la negociación colectiva y del la huelga, es decir, el quién, el dónde, el para qué, el cómo, el cuándo y el qué de la actividad sindical ${ }^{16}$, incluido el nivel de extensión de la cobertura de los instrumentos colectivos.

\footnotetext{
11 América Latina tiene un modesto promedio del 9\% de cobertura de contratación colectiva en el año 2010. Véase CARRILLO (2015), p. 5.

12 Sobre los denominados sistemas de autonomía colectiva plena abstención legislativa, véase BAYLOS (1991), pp. 39 y ss.

13 Véase Kahn-Freund (1987), p. 382; Davies y Freedland (1987), p. 33, y Dukes (2014), pp. 69 y ss.

${ }^{14}$ ERMIDA (1991), p. 6.

15 ERMida (1991), pp. 6 a 9.

${ }^{16}$ Gamonal (2011), pp. 30 y ss. El reglamentarismo puede ser orgánico o funcional, según recaiga en el aspecto organizativo del sindicato o en su accionar colectivo. Op. cit., p. 31.

Como señala Ermida, respecto del derecho de huelga en las sociedades latinoamericanas, la Constitución realiza el "trabajo lindo" de consagrar el derecho con bastante amplitud y la ley el "trabajo sucio" o
} 
Un estudio comparado sobre todos los sistemas de negociación ramal excede la extensión de un trabajo a publicarse en una revista como esta. Por ello, hemos seleccionado dos sistemas que a nuestro criterio permiten buscar una respuesta a las interrogantes planteadas, así en un primer momento nos centraremos en el modelo uruguayo (una notable excepción en América Latina ${ }^{17}$ ) para luego abocarnos al modelo italiano, caracterizados porque han compartido una característica en común de abstención legislativa o de ser sistemas de autonomía colectiva plena. En el caso italiano la independencia y complejidad del sistema es mayor que en el del Uruguay ${ }^{18}$, pero en ambos la regulación estatal del fenómeno sindical ha sido muy escasa destacándose la autonomía de los actores sociales y la negociación por rama de actividad ${ }^{19}$.

Cabe precisar que no nos referiremos a los sistemas de negociación del sector público ${ }^{20}$, sino sólo al sector privado.

En el acápite que sigue estudiaremos los principales lineamientos del modelo uruguayo. Luego, analizaremos el caso italiano. Finalizaremos con las enseñanzas que podemos extraer de estas experiencias y su aplicabilidad a la realidad latinoamericana.

\section{El caso uruguayo: los Consejos de Salarios}

El modelo de abstención legislativa uruguayo se ha caracterizado por una alta autonomía en la regulación de las relaciones colectivas, producto de un abstencionismo normativo estatal en esta materia ${ }^{21}$. Este modelo ha sido conocido también como el de los Consejos de Salarios ${ }^{22}$ y ha sido un modelo en el que

un poco más desagradable de establecer restricciones mayores o menores según el caso. Véase ERMIDA (1991), p. 133.

Sobre el reglamentarismo excesivo en América Latina consultar VILLAVICENCIO (2014), pp. 561 a 567.

17 ERMIDA (1991), p. 6.

18 Gamonal (2011), pp. 35 y 36.

19 También Gran Bretaña se caracterizó por ser un sistema de abstención legislativa. Sin embargo, este modelo desde los años ochenta del siglo pasado ha sufrido grandes cambios, producto de las políticas reglamentaristas adoptadas en su momento por el Gobierno de Thatcher, debilitándose el sindicalismo y disminuyendo la cobertura de la negociación colectiva. Para una síntesis de las enmiendas legislativas neoliberales en dicho país véase WeDDERBURN (1998), pp. 44 y ss.

El año pasado se ha dictado una nueva ley sindical en Gran Bretaña (Trade Union Act/2016) y la doctrina no ha dudado en denunciar el autoritarismo del legislador británico que nuevamente ha limitado la actividad concertada de los trabajadores. Al respecto, véase Bogc (2016), pp. 299-336.

20 Tanto en Uruguay (Ley N ${ }^{\circ}$ 18.508) como en Italia (d. Igs. 29/1993) hay sistemas de negociación colectiva especiales para el sector público.

21 RASO (1998), p. 126.

22 Loustaunau (2010a). 
ha predominado la negociación por área de actividad ${ }^{23}$, siendo la negociación por empresa de relevancia menor ${ }^{24}$.

En Uruguay hasta hace pocos años el marco regulatorio general estaba dado por el artículo 57 de la Constitución, que consagra el fomento de los sindicatos gremiales y la huelga como un derecho gremial, y los Convenios $N^{\circ}$ s. 87, 98, 151 y 154 de la OIT ratificados los dos primeros en 1953 y los dos restantes en 1989.

A nivel legislativo las normas eran escasas ${ }^{25}$, siendo destacable la importancia de los Consejos de Salarios instituidos por ley en $1943^{26}$ y que han influido en la conformación del sistema de relaciones colectivas, especialmente en la negociación colectiva por actividad ${ }^{27}$.

Recién aprobada la ley de Consejos de Salarios fue vista por los sindicatos como un desconocimiento estatal al movimiento sindical y a los convenios colectivos, dado que se entendía que los Consejos verían temas como los salarios y las categorías profesionales y que la contratación colectiva directa y bilateral de las partes no podría abordar estos temas. Sin embargo, rápidamente se interpretó que los Consejos de Salarios sólo tratarían del salario mínimo y las partes, a través de los convenios colectivos bilaterales, podrían tratar todos los temas. En definitiva, esta ley fue un éxito y potenció la actividad negociadora de los sindicatos ${ }^{28}$.

La doctrina uruguaya distingue tres manifestaciones de la negociación colectiva en este país: (1) la negociación colectiva típica o pura, comprensiva de procesos bilaterales, no regulados, autónomos y no institucionalizados; (2) el modelo de negociación colectiva atípica de los Consejos de Salarios, conformando un modelo trilateral de negociación, institucionalizado y regulado heterónomamente. Los resultados de estas negociaciones eran aprobadas a través de laudos homologados por el Poder Ejecutivo y con eficacia erga omnes y (3)

\footnotetext{
${ }^{23}$ La cobertura de la negociación en Uruguay, para el año 2013, era de casi un 100\% según la Oıт. Véase Oıт "La cobertura de la negociación colectiva ha disminuido como consecuencia de la crisis financiera mundial", 2015: http://www.ilo.org/global/about-the-ilo/newsroom/news/WCMS_415628/ lang--es/index.htm (página consultada el 20 de septiembre de 2017).

Véase también OIT "Trends in collective bargaining coverage: stability, erosion or decline?", 2015: http://www.ilo.org/wcmsp5/groups/public/---ed_protect/---protrav/---travail/documents/publication/ wcms_409422.pdf (página consultada el 20 de septiembre de 2017).

24 Rosenbaum (2010), p. 61.

${ }^{25}$ Leyes $N^{\circ}$ s. 9.675 de 1937; 13.556 de 1966 y 16.170 de 1990, citadas por Raso Delgue, op. cit. 1998, p. 127.

${ }^{26}$ Ley No 10.449 de 1943.

27 Barbagelata; Rosenbaum y Garmendia (1998), pp. 61 a 63 y 94.

28 PLÁ (1999), pp. 1499 y 1500.
} 
la negociación colectiva de carácter mixto o ecléctico, por el deslizamiento del contenido originario de los Consejos de Salarios (fijación del salario mínimo), provocado por las negociaciones bilaterales previas de los actores sociales cuyos resultados eran sometidos luego a los Consejos de Salarios con la finalidad de extender su eficacia a la rama de actividad ${ }^{29}$.

Como vemos, los Consejos de Salarios han sido claves en la conformación de las relaciones colectivas uruguayas y por ello se habla de un abstencionismo aparente en este país ${ }^{30}$, dada la relevancia vital de esta legislación, aunque la doctrina uruguaya caracterizaba la legislación de este país como asistemática, fragmentaria y puntual ${ }^{31}$.

La ley de Consejos de Salarios (en adelante Consejos) No 10.449, trataba del salario mínimo y en su artículo $5^{\circ}$ creaba estos Consejos con el objetivo de fijar los montos mínimos de los salarios que deben percibir los trabajadores, empleados u obreros del comercio, la industria, oficinas y escritorios de propiedad privada y los servicios públicos no atendidos por el Estado.

Para estos efectos, se disponía que, en cualquier época, el Poder Ejecutivo podría provocar de oficio o a petición de parte, por intermedio del Ministro competente, la constitución de los Consejos.

Esta ley le otorgaba también a la tercera parte de los obreros de una industria o comercio registrados en las planillas de trabajo, a los patronos y los sindicatos patronales o las agrupaciones obreras con personería jurídica o reconocida por el Poder Ejecutivo, el derecho de petición no vinculante a la autoridad para la constitución de estos Consejos.

El artículo 15 de la ley establecía que los Consejos fijarían el salario mínimo aplicable a cada categoría de trabajo sometida a sus jurisdicciones, por hora o por jornada, o por semana, o por mes, o por pieza, según fuera necesario o lo consideraran conveniente. El artículo $6^{\circ}$ estatuía que el Poder Ejecutivo clasificaría en grupos las actividades enumeradas (comercio, la industria, oficinas y escritorios de propiedad privada y los servicios públicos no atendidos por el Estado) y para cada uno de ellos funcionaría un Consejo constituido por siete miembros: tres designados por el Poder Ejecutivo en Consejo de Ministros, dos por los patronos y dos por los obreros, e igual número de suplentes.

El artículo $9^{\circ}$ disponía que cada Consejo una vez constituido y dentro del plazo que en cada caso se fijará, haría la clasificación por profesiones y categorías

\footnotetext{
29 Barbagelata et al. (1998), pp. 60 y 61.

30 ERMida (2010), p. 8.

31 ERMida (2010), p. 6.
} 
de los trabajadores que integran el grupo respectivo, la que sería tomada como base para la fijación de los salarios mínimos.

En los primeros años de aplicación de la ley fueron convocados los consejos y coincidiendo con un período de desarrollo industrial, los salarios crecieron y las condiciones de los trabajadores mejoraron sustancialmente ${ }^{32}$. Luego, desde fines de los años cincuenta, los salarios comenzaron a estancarse hasta que en 1968 comenzó una política estatal de restricción salarial, decretándose una congelación de los salarios ${ }^{33}$. Desde la dictadura militar en 1973 y hasta 1985 no fueron convocados los Consejos, limitándose la negociación colectiva y los sindicatos ${ }^{34}$.

Una vez recuperada la democracia en 1985 se volvió a convocar los Consejos fortaleciéndose, nuevamente, las organizaciones sindicales hasta los años noventa en donde, producto de las políticas neoliberales dejaron de convocarse hasta el año 2005 en que el nuevo Gobierno de izquierda los vuelve a convocar ${ }^{35}$.

En todas estas idas y venidas, el sindicalismo ha dependido de la convocatoria o no a los Consejos. Por ello se dice que los Consejos no sólo son un medio de fijación de salarios mínimos sino también "un verdadero elemento promotor del diálogo social y de las relaciones colectivas de trabajo" ${ }^{\prime 36}$. En el mismo sentido, se ha indicado que los Consejos de Salarios conforman un "perfil uruguayo" de negociación colectiva convirtiéndose en el verdadero eje y sostén del sistema ${ }^{37}$.

Desde el año 2005, el panorama ha tendido a cambiar con la dictación de algunas leyes sindicales, a saber, la Ley $N^{\circ} 17.940$, de 2006, sobre normas de fomento de la actividad sindical y de reinstalación o reintegro en caso de discriminación antisindical por medio de un procedimiento especial; la Ley № 18.508, de 2009, sobre negociación colectiva en el sector público y la Ley $N^{0} 18.566$, del mismo año, sobre negociación colectiva en el sector privado. Por último, en el año 2009 se aprobó el Convenio № 135 de la OIT. Cabe agregar, el Decreto № 165/006 del 2006 que regula la desocupación (en casos de ocupación de los lugares de trabajo) y la prevención de los conflictos laborales ${ }^{38}$.

El elemento clave ha sido que, desde la Ley № 18.566 de 2009, la convocatoria a Consejos de Salarios puede ser provocada obligatoriamente por las

\footnotetext{
32 Loustaunau (2010a), p. 16.

33 Loustaunau (2010a), p. 17.

34 Loustaunau (2010a), p. 17.

35 Loustaunau (2010a), p. 18.

36 Loustaunau (2010a), p. 18.

37 Barbagelata et al. (1998), p. 63.

38 Sobre estas reformas vid. los ensayos contenidos en la obra: AA.VV. (2010).
} 
organizaciones representativas del sector de la actividad correspondiente, debiendo convocarlos el Poder Ejecutivo dentro de los 15 días siguientes a esta petición (nuevo artículo $5^{\circ}$ de la Ley $N^{\circ} 10.449$ agregado por la Ley $\left.\mathrm{N}^{\circ} 18.566\right)$.

La Ley N $N^{\circ} 18.566$ establece un Consejo Superior Tripartito como órgano de coordinación y gobernanza de las relaciones laborales (artículo $7^{\circ}$ ), integrado por 9 delegados del Poder Ejecutivo, 6 de las organizaciones más representativas de trabajadores y 6 de las más representativas de empleadores $\left(\right.$ artículo $8^{\circ}$ ). Este Consejo Superior efectuará la clasificación de los grupos de negociación tripartita por rama de actividad o cadenas productivas, designando, en su caso, las organizaciones negociadoras en cada ámbito (artículo 10 letra b) y deberá considerar y pronunciarse sobre cuestiones relacionadas con los niveles de negociación tripartita y bipartita (artículo 10 letra d).

En cuanto a la negociación por rama de actividad, la Ley $N^{\circ} 18.566$ dispone que podrá realizarse por medio de los Consejos de Salarios o por medio de la negociación colectiva bipartita (artículo 11).

Los Consejos de Salarios podrán fijar el monto de los salarios mínimos y establecer las condiciones de trabajo para el caso que sean acordadas por los delegados de empleadores y trabajadores del grupo salarial respectivo $^{39}$. Las decisiones de los Consejos surtirán efecto en el respectivo grupo de actividad una vez que sean registradas y publicadas por parte del Poder Ejecutivo. No será necesaria la convocatoria de Consejos en aquellas actividades o sectores en que esté vigente un convenio colectivo que hubiera sido debidamente concertado por las organizaciones de empleadores y trabajadores más representativas de la actividad o sector (nuevo artículo $5^{\circ}$ de la Ley $N^{\circ} 10.449$ agregado por la Ley $N^{\circ} 18.566$ ).

El Consejo Superior Tripartito efectuará la clasificación por grupos de actividad, y para cada uno de ellos funcionará un Consejo de Salarios constituido por siete miembros: tres designados por el Poder Ejecutivo, dos por los patronos y dos por los trabajadores, e igual número de suplentes (nuevo artículo $6^{\circ}$ de la Ley $N^{\circ} 10.449$ agregado por la Ley $\left.N^{\circ} 18.566\right)$.

Para efectos de determinar la mayor representatividad, la Ley $N^{\circ} 18.566$ establece que, cuando exista más de una organización que se atribuya la legitimidad para negociar y no medie acuerdo entre ellas, la legitimación para negociar se reconoce a la organización más representativa, en atención a los criterios de antigüedad, continuidad, independencia y número de afiliados de

\footnotetext{
${ }^{39}$ La Ley $N^{0} 16.002$ había ampliado las materias de conocimiento de los consejos de salarios a las condiciones de trabajo. Véase Loustaunau (2010b), p. 19.
} 
la organización. En la negociación colectiva de empresa, cuando no exista organización de los trabajadores, la legitimación para negociar recaerá en la organización más representativa de nivel superior (artículo 14).

En cuanto a la relación entre contrato colectivo ramal y contratos colectivos de menor rango, así como respecto del contrato individual, se dispone que las partes podrán negociar por rama o sector de actividad, empresa, establecimiento o cualquier otro nivel que estimen oportuno. La negociación en los niveles inferiores no podrá disminuir los mínimos adoptados en los convenios colectivos de nivel superior, salvo lo dispuesto en el Consejo de Salarios respectivo (artículo 15) y los convenios colectivos no podrán ser modificados por contrato individual o acuerdos plurisubjetivos en perjuicio de los trabajadores. El convenio colectivo por sector de actividad, celebrado por las organizaciones más representativas, es de aplicación obligatoria para todos los empleadores y trabajadores del nivel de negociación respectivo, una vez que sea registrado y publicado por el Poder Ejecutivo (artículo 16). Por último, la vigencia de los convenios colectivos será establecida por las partes de común acuerdo, quienes también podrán determinar su prórroga expresa o tácita y el procedimiento de denuncia. El convenio colectivo cuyo término estuviese vencido, mantendrá la plena vigencia de todas sus cláusulas hasta que un nuevo acuerdo lo sustituya, salvo que las partes hubiesen acordado lo contrario (artículo 17).

Respecto de esta nueva legislación se hace presente que, en lo estrictamente sindical, el modelo uruguayo no ha cambiado, salvo en el caso de las nuevas leyes sobre negociación colectiva que no dejan espacio para hablar de un sistema propiamente abstencionista ${ }^{40}$. Respecto del derecho de huelga, el ordenamiento de este país mantiene su tradicional característica de abstencionismo legislativo ${ }^{41}$.

Como balance general, se habla de una regulación modesta o discreta, que sólo estatuye algunas normas mínimas de promoción y protección de la actividad sindical ${ }^{42}$, manteniendo un espacio amplio de autonomía de los sindicatos ${ }^{43}$. Es cierto que existe normativa tanto en la Constitución como en los Convenios OIT ratificados por Uruguay, y que las nuevas leyes contemplan regulaciones mínimas del fenómeno sindical, lo que podría desplazar la calificación de este sistema de uno abstencionista a uno mixto con leyes

\footnotetext{
40 Ermida (2010), p. 12.

${ }^{41}$ Castello (2010), inédito, p. 2.

42 Loustaunau (2010a), p. 119.

43 Se habla de "ligera reglamentación". Véase Loustaunau (2010ª), p. 33.
} 
sindicales que fomentan y respetan el principio de libertad sindical, sin caer por ello en un reglamentarismo asfixiante del fenómeno ${ }^{44}$.

Sin embargo, si contextualizamos esta regulación dentro del derecho de América Latina, aún puede ser considerado un sistema abstencionista en comparación con los otros países de nuestro sub continente. Por ejemplo, si revisamos el Manual de Derecho Sindical de Osvaldo Mantero de San Vicente, el marco normativo de la organización sindical sigue siendo la Constitución y el Convenio 87 de la OIT y las tímidas normas de la Ley $N^{\circ} 17.940$ sobre despido antisindical, permiso sindical, retención de cuotas, derecho de colocar avisos informativos y derecho de transmitir información a los trabajadores en el lugar de trabajo ${ }^{45}$, lo cual contrasta con las leyes de los países vecinos que regulan en detalle a las organizaciones sindicales. Algo similar sucede con el derecho de huelga reconocido a nivel constitucional y por tratados internacionales ${ }^{46}$. Es decir, las nuevas regulaciones han incidido sobre todo en la negociación colectiva y los Consejos de Salarios, perfeccionando el sistema de la Ley No 10.449 .

Como ya enfatizamos, un dato clave en el éxito actual del sistema es la posibilidad de que las partes sociales puedan obligar al Ministerio a convocar a los Consejos de Salarios. En ese sentido, la Ley No 18.566 resulta ser una pieza clave del sistema ${ }^{47}$ y la intervención estatal no es invasiva sino de árbitro y guardián del sistema, lo cual es plenamente consecuente con un enfoque pluralista de las

44 Gamonal (2011), pp. 40 y 41.

45 Mantero (2015), pp. 105 a 178.

46 Artículos 57, 72 y 332 de la Constitución Nacional del Uruguay, normas internacionales como el Convenio 87 de la OIT y la Declaración Sociolaboral del Mercosur, algunas normas legales aisladas que regulan especificidades en cuanto a los efectos de la huelga, por ejemplo, que el tiempo en huelga igual genera vacaciones pagas (Ley $N^{\circ}$ 12.950) o que el trabajador en huelga no tiene derecho a subsidio de desempleo (Ley $N^{\circ} 15.180$ ) y por cierto criterios jurisprudenciales sobre el alcance de este derecho. También ha existido alguna regulación de tipo reglamentario. Véase MANTERO (2015), pp. 214 a 218 , y 226 y 227, y Gari y Pérez del Castillo (2016), pp. 117 y 118.

${ }^{47}$ Cabe precisar que los empleadores hicieron una queja ante la OIT durante la tramitación de la Ley No 18.566. La OIT (caso No 2.699 de marzo de 2010) hizo varias observaciones a le ley: 1) Que todas las partes (tengan o no personería gremial) deben ser responsables por la violación del derecho de reserva en el caso de las informaciones confidenciales; 2) Que el Consejo Superior Tripartito debiera estar integrado por igual número de miembros de los tres sectores; 3) Que la determinación del nivel de negociación debe ser de las partes y no del Consejo Superior Tripartito; 4) Que en la negociación de empresa la negociación con la organización de nivel superior debería efectuarse sólo cuando haya representación sindical en la empresa; 5) En cuanto a los efectos del convenio de sector se le pide al Gobierno que en el registro y publicación de los mismos sólo se realice un cumplimiento de mínimos legales y cuestiones de forma y 6) Que la duración de los convenios es materia de las partes, sobre todo respecto del mantenimiento de su vigencia una vez vencido. Véase Rosenbaum (2010), p. 67. 
relaciones industriales, que valora el conflicto como inevitable y legítimo y que es respetuoso de la autonomía de los actores sociales ${ }^{48}$.

\section{El caso italiano: el Ordenamiento Intersindical}

El caso del Ordenamiento Intersindical italiano es el mejor ejemplo del abstencionismo legislativo ${ }^{49}$.

En Italia la autonomía colectiva ha tenido un gran desarrollo producto de la carencia de una legislación orgánica en materia sindical, no obstante que las normas constitucionales sobre libertad sindical y huelga delegan en la ley la regulación de diversos aspectos del derecho de negociación colectiva y de autotutela $\mathrm{a}^{50}$.

En efecto, en la Constitución italiana encontramos dos normas centrales en materia sindical, los artículos 39 y 40 . El primero establece que la organización sindical será libre y sus incisos segundo a cuarto especifican que no se podrá imponer a los sindicatos otra obligación que la de registrarse ante departamentos locales o centrales, según lo que la ley disponga. Será condición para el registro que los estatutos de los sindicatos sancionen un régimen interior fundado en los principios democráticos. Los sindicatos registrados tendrán personalidad jurídica y podrán, representados unitariamente en proporción a los respectivos afiliados inscritos, concertar convenios colectivos de trabajo con efectos obligatorios para todos los pertenecientes a las categorías a que se refiera el convenio. Por su parte, el artículo 40 dispone que el derecho de huelga se ejercitará en el ámbito de las leyes que lo regulen ${ }^{51}$.

Sin embargo, las leyes no se dictaron y el sistema ha funcionado en base a los acuerdos de las multisindicales de trabajadores y empleadores. El sistema contemplado y reenviado a la ley, en el artículo 39 inciso segundo y siguientes, no ha sido jamás desarrollado por el legislador ${ }^{52}$ y la doctrina ha sido vital para darle racionalidad y construir un sistema sindical frente a lo que Francesco Santoro-Passarelli denominaba "derecho sin normas" ${ }^{\text {"53 }}$.

\footnotetext{
48 RASO (2014), pp. 423 y 424.

${ }^{49}$ La cobertura de la negociación colectiva en Italia, para el año 2013, era de más de un 80\% según la OIT . Véase OIT "Trends in collective bargaining coverage: stability, erosion or decline?", 2015: http://www.ilo.org/wcmsp5/groups/public/---ed_protect/---protrav/---travail/documents/publication/ wcms_409422.pdf (página consultada el 20 de septiembre de 2017).

50 Persiani (1991), p. 12.

51 RAMOS (2009), p. 214.

52 Mazzotta (2017), p. 33.

53 Santoro-Passarelli (2007), p. 15.
} 
Las tres grandes confederaciones sindicales de trabajadores $\left(\mathrm{CGIL}^{54}, \mathrm{CISL}^{55}\right.$ y UIL ${ }^{56}$ ) se han opuesto a cualquier intento de ley que regule lo dispuesto en el artículo 39 incisos segundo a cuarto de la Constitución, por temor a un excesivo intervencionismo estatal en la autonomía colectiva privada. Cuando en 1970 se dictó el Estatuto de Trabajadores (Ley No 300), las normas de fomento sindical a nivel de empresa fueron bienvenidas por estas confederaciones, dado que promovían el sindicalismo sin concretar el mandato de negociación ramal del señalado artículo $39^{57}$.

Ante este panorama, en la década de los cincuenta, el profesor Francesco Santoro-Passarelli realizó una reconstrucción del derecho colectivo desde el derecho privado, frente a la inactivación legislativa. Esta reconstrucción de la autonomía colectiva en clave privada se basaba en la noción de intereses colectivos $^{58}$ y en que el contrato colectivo era de derecho común ${ }^{59}$. En alguna medida, esta reconstrucción fue expresión del contexto histórico que buscaba superar las categorías del derecho neo corporativista fascista y de los temores de las grandes centrales sindicales de que la regulación estatal pudiera afectar su autonomía ${ }^{60}$.

Luego, en los años sesenta, Gino Giugni postuló como modelo explicativo del sistema la teoría del "Ordenamiento Intersindical" ${ }^{61}$, a fin de otorgar certeza jurídica dentro de su propio ámbito al sistema sindical, con independencia de la falta de legislación en la materia. La teoría del Ordenamiento Intersindical constituye más bien una reconstrucción desde el derecho público, en base a los intereses sociales tutelados por este ordenamiento y que, para algunos, en cierta forma integra o complementa la teoría privatista de Santoro-Passarelli ${ }^{62}$. Otros

\footnotetext{
${ }^{54}$ La CGIL es la Confederación General Italiana del Trabajo, fuertemente vinculada al partido comunista italiano. Es la confederación más antigua y con mayor cantidad de socios, fundada en 1906.

${ }^{55}$ La CISL es la Confederación Italiana de Sindicatos de Trabajadores, de inspiración católica y laica, fundada en 1948 como escisión de la CGIL, es la segunda confederación más importante.

56 La UIL es la Unión Italiana del Trabajo, de inspiración socialdemócrata, fundada en 1950 en base a la Federación Italian del Trabajo que en 1948 se había escindido de la CGIL, es la tercera confederación más importante.

57 Santoro-Passarelli (2007), pp. 20 y 21.

58 Santoro-Passarelli (1963), p. 22.

59 Persiani (1991), pp. 69 a 73.

60 Santoro-Passarelli (2007), p. 16.

61 Givgni (2004).

62 LATTARI (2016), p. 27.

La reconstrucción de GIUGNI es vista por algunos en continuidad con la interpretación de SANTOROPassarelli, como un desarrollo natural de su teoría privatista. Otros, como Sciarra, disienten de esta perspectiva. Véase, Sciarra (2009), pp. 257 y 258.
} 
autores han enfatizado que la reconstrucción de Santoro-Passarelli reafirma la perspectiva civilista, basada en el contrato y en un credo legalista y estatista, a diferencia de Giugni, quien desde una perspectiva pluri ordinamental amplía el viejo paisaje civilístico enfatizando no sólo los derechos subjetivos, las relaciones y los contratos, sino también los "fenómenos organizativos", estudiando al sindicalismo como un sistema espontáneo y en crecimiento, al tenor de líneas de originalidad normativa ${ }^{63}$.

Giugni se sirve de la noción de "ordenamiento jurídico" formulada en 1919 por Santi Romano, para explicar la autonomía colectiva y su evolución en el sistema italiano ${ }^{64}$. Esta concepción permite el estudio de las realidades jurídicas extraestatales, caracterizadas por su efectividad real en la vida social, lo que permite encuadrar las relaciones sindicales en la noción de Ordenamiento Intersindical, es decir, en un ordenamiento independiente y original respecto del ordenamiento del Estado ${ }^{65}$.

Lo anterior es deducido al constatarse en la realidad sindical italiana que el Ordenamiento Intersindical contiene todos los elementos de un orden jurídico, a saber: la existencia de órganos legitimados para producir normas de acuerdo a criterios internos de legitimación; de órganos competentes para aplicarlas, y de instrumentos para sancionar su inobservancia ${ }^{66}$.

Giugni explicaba que las relaciones entre empresarios, organizaciones sindicales y poderes públicos, normalmente están dotadas de una relativa estabilidad (por lo menos en las reglas sobre producción normativa) y de, además, una relativa autonomía respecto de otros sectores de la vida social, constituyendo una "institución" en la terminología de Santi Romano, precisando que a cada institución corresponde un ordenamiento y viceversa ${ }^{67}$, lo que también es aplicable al Ordenamiento Intersindical.

Tanto el ordenamiento estatal como el intersindical pueden regular una misma materia, caso en el cual podemos estar frente a cualquiera de las tres alternativas siguientes. Primero, si ambas valoraciones normativas coinciden no se produce problema alguno. Segundo, si dichas valoraciones son contradictorias se produce un conflicto de lealtad que determina que una norma es ineficaz en uno de los ordenamientos, no obstante su validez en el otro. Tercero, que las dos valoraciones normativas sean diferentes y que, por ende, no estén en conflicto.

\footnotetext{
${ }^{63}$ Grossi (2007), pp. 259 y 260.

${ }^{64}$ Givgni (1983), p. 26.

65 Givgni (1983), pp. 26 y 27.

${ }^{66}$ Carinci et al. (1994), p. 4.

67 Givgni (1997), p. 16.
} 
En este caso, lo que para un ordenamiento es un comportamiento "obligado" para el otro cae en la esfera de una "mera libertad"68. Por ello, gran parte de las relaciones industriales pueden ser integradas a la luz del ordenamiento estatal como meras relaciones obligatorias de origen contractual de derecho privado, mientras que, si se analiza más en profundidad, las mismas aparecen radicadas en razones de equilibrio que trascienden la fuerza de la relación obligatoria y de la responsabilidad patrimonial del derecho civil ${ }^{69}$.

La principal crítica a esta teoría se funda en la utilización de la noción de ordenamiento como construcción dogmática junto a la noción de pluralidad de ordenamientos jurídicos ${ }^{70}$. Lo anterior, por la contradicción lógica producida al postular, por un lado, un ordenamiento sindical autónomo de carácter pre-estatal y originario, junto a la idea de un ordenamiento estatal absorbente y general que subsume al Ordenamiento Intersindical de carácter particular, integrándolo en su seno ${ }^{71}$. De esta forma, algunos autores postulan una concepción pluralista derivada, que afirma que los ordenamientos autónomos obtienen legitimidad no en forma originaria sino derivada del reconocimiento estatal $^{72}$. En este contexto, el ordenamiento intersindical se fundaría en una delegación o autorización estatal a los interlocutores sociales ${ }^{73}$.

No obstante las críticas, en las décadas de los sesenta y setenta fue enorme la importancia de la construcción teórica del Ordenamiento Intersindical, utilizada como un instrumento eficaz para comprender la dinámica de las relaciones sindicales ${ }^{74}$ y para la interpretación del derecho estatal italiano ${ }^{75}$.

El Ordenamiento Intersindical ha estimulado y cumplido una función de innovación en el derecho estatal; realizando este último, por su parte, labores de fomento y de sustento de la autonomía colectiva y de integración de las normas del Ordenamiento Intersindical. Desde fines de los años sesenta, se observa una tendencia hacia una mayor regulación e influencia del derecho

\footnotetext{
68 GivgNi (1997), p. 17.

69 Givgni (1997), p. 17.

70 Baylos (1991), p. 43.

71 Vardaro (1984), pp. 103 a 105, y Nogler (1997), p. 60.

72 Mantero (1995), pp. 284 y 285.

73 Desde una perspectiva teórica Tarello criticó en su momento a Giugni por juntar en una misma propuesta teorías irreconciliables, como la del ordenamiento jurídico de Santi Romano como "derecho vivo" y la teoría institucionalista de los franceses. Véase Tarello (2002), pp. 98 y 99.

74 CARINCl et al. (1994), pp. 4 y 5.

75 TARello (1995), p. 364.
} 
estatal $-y$, por ende, a una pérdida de autonomía- en el Ordenamiento Intersindical italiano ${ }^{76}$.

En efecto, en los últimos 40 años las relaciones entre el ordenamiento estatal y el intersindical han sido de coordinación y de sustento, y de fisuras desde el año 2011. Por otro lado, dentro del mismo Ordenamiento Intersindical, se han producido fisuras internas a nivel de la contratación de empresa o de segundo nivel.

En el sistema corporativo de la época de Mussolini, el contrato colectivo era una fuente más del derecho estatal, subordinada a la ley y con efectos generales. Por cada categoría profesional se reconocía a un sindicato único como representante de los trabajadores. Con la suspensión del régimen corporativo, en 1943, esta regulación del contrato colectivo resultó inaplicable (art. 2067 y ss. del Código Civil), dado también el artículo 39 de la nueva Constitución italiana de posguerra (1947). Como no se ha dictado la legislación que contempla esta norma (art. 39), el encuadramiento del contrato colectivo en Italia se enmarca hasta nuestros días, desde la perspectiva estatal, en el derecho común o civil de los contratos (sin eficacia normativa y sin erga omnes) tanto a nivel de categoría o ramal y de empresa ${ }^{77}$.

Con todo, la legislación postconstitucional ha intervenido en distintas formas para reforzar la eficacia de la contratación colectiva, sin por ello llegar a imponer una eficacia erga omnes como lo mandata el artículo 39. Primero con la Ley Vigorelli, No 741, de 1959 (denominada de esta forma por el nombre de su autor), que extendió la eficacia subjetiva de los contratos colectivos por categoría autorizando al Gobierno para promulgar decretos legislativos delegados que recogiesen el contenido de los mismos. Esta ley tuvo una duración limitada, ya que cuando se la quiso prorrogar (por la Ley $N^{\circ} 1027$, de 1960), la Corte Constitucional la estimó inconstitucional por establecer el erga omnes por medio de un sistema distinto al dispuesto en el artículo 39 inciso cuarto, considerando para estos efectos que la Ley Vigorelli de 1959 era constitucional sólo por ser excepcional, pero su prórroga la convertía en un recurso permanente (sentencia $N^{0} 106$ de 1962) ${ }^{78}$.

Con el Estatuto de Trabajadores de 1970 se reconocieron prerrogativas a los sindicatos en el lugar de trabajo, en las empresas con más de 15 trabajadores ${ }^{79}$,

\footnotetext{
76 CARINCI et al. (1994), p. 5.

Sobre la necesidad de regulación en el sistema italiano, especialmente en materia de representación sindical, vid. MARIUCCI (1991), pp. 15 a 57.

77 Corso (2017), pp. 161 y 162.

78 Santoro-Passarelli (2007), p. 22.

79 D'ANTONA (2000), pp. 402 y 403.
} 
por ejemplo, el derecho de informar a los trabajadores y de colocar y pegar información ${ }^{80}$, el derecho a permiso sindical de los representantes ${ }^{81}$, a una tutela especial en caso de transferencia y despido de dirigentes ${ }^{82}$ y el derecho a tener una sede sindical en las empresas con al menos 200 trabajadores $^{83}$. Además, se dispuso que el sindicato puede ejercer una serie de derechos instrumentales, como convocar a asambleas, hacer consultas o referendos, actividad proselitista y recaudar las cuotas sindicales ${ }^{84}$. También el Estatuto de Trabajadores reprime las conductas antisindicales de los empleadores por medio de un procedimiento tutelar especial ${ }^{85}$. Por último, pero no por ello menos importante, el Estatuto contempla en su artículo 19 la representación sindical a nivel de empresa ${ }^{86}$.

Luego, el legislador reconoció una autoridad negocial a los sindicatos en situaciones excepcionales, como en el caso de la gestión de las crisis empresariales ${ }^{87}$. De esta forma, la negociación colectiva desarrollada en el Ordenamiento

\footnotetext{
80 Mazzotta (2017), p. 61.

81 Mazzotta (2017), p. 62.

${ }^{82}$ Mazzotta (2017), p. 64.

${ }^{83}$ Mazzotta (2017), p. 61.

${ }^{84}$ MazzotTa (2017), pp. 71 a 75.

85 Mazzotta (2017), pp. 75 y ss.
}

${ }^{86}$ Este artículo 19 originalmente disponía que podían constituirse a nivel de empresa representaciones sindicales RSA (Rappresentanze Sindicali Aziendali) aquellas organizaciones de trabajadores inscritas en el ámbito de las confederaciones más representativas u otras organizaciones sindicales no afiliadas, que hubiesen firmado el contrato colectivo nacional o provincial aplicable a la empresa. Este reconocimiento era funcional a la utilización de los derechos que contemplaba el Estatuto de Trabajadores a favor de la actividad sindical a nivel de empresa en sus arts. 20 y ss., pero dejaba plena libertad en cuanto a la forma organizativa específica por la que optaran los trabajadores. Luego de un referéndum abrogatorio en 1995, se suprimió parte del artículo 19 quedando vigente que sólo podían constituir RSA las asociaciones sindicales que hayan firmado el contrato colectivo aplicable a la empresa, de cualquier nivel, incluso contrato colectivo de empresa. Posteriormente, la Corte Constitucional por medio de una sentencia aditiva, especificó que basta que la agrupación sindical haya "participado" en las tratativas del contrato colectivo, sin que lo haya firmado necesariamente, para constituir una RSA (véase Guarriello (2014), pp. 767-781).

El sistema de representación en la empresa entró en profunda crisis en los años 80, por muchos motivos. Por un lado, la falta de unidad entre las confederaciones de trabadores, por otro, la superación del sistema taylorista erosionó el trabajo estandarizado, desplazó muchos puestos de trabajo al sector servicios, con menos tradición de RSA, lo cual se ha reforzado con la robotización y automatización de procesos. Por ello, las Confederaciones buscaron respuesta y soluciones y contemplaron la creación de las Representaciones Sindicales Unitarias (RSU) previstas en un protocolo de 1991 y reguladas en el protocolo de 1993 y en sucesivos acuerdos interconfederales, incluyendo el actual Texto Único de la Representación del 2014. Su sentido es tener representaciones sindicales unitarias en el lugar de trabajo (empresas con más de 15 trabajadores), electas por todos los trabajadores, sean o no socios de sindicatos. Véase GiugNi (2015), pp. 88 a 92; Corso (2017), pp. 58 a 60, y LATTARI (2016), pp. 45 a 49.

87 D'ANTONA (2000), p. 403. 
Intersindical por fuera del marco del artículo 39 de la Constitución, fue reconocida por el legislador como parámetro de "adecuación social" y se le otorgó nuevas funciones que la doctrina denominó "constitutivas" ${ }^{18}$. Esta legislación postconstitucional reconoció el sistema contractual colectivo intersindical voluntario y autolegitimado, haciendo suyos, en casos específicos, los equilibrios que produce este sistema contractual ${ }^{89}$.

También se le ha atribuido a la contratación colectiva un parámetro de "adecuación social" ${ }^{\prime 90}$ por medio de técnicas de incentivo ${ }^{91}$. De esta forma se otorgan beneficios a los empleadores que apliquen los estándares y beneficios negociados por los contratos colectivos. Por ejemplo, los contratistas de obras públicas deben aplicar los estándares de la contratación colectiva a sus trabajadores ${ }^{92}$.

Más adelante, poco a poco se fue extendiendo la competencia sindical a materias de interés público, como la gestión del mercado de trabajo o la programación territorial de las inversiones ${ }^{93}$. Por otra parte, el Decreto Legislativo $N^{\circ}$ 40, de 2 de febrero de 2006, enmendó el número 3 del artículo 360 del código de procedimiento civil, permitiendo el recurso de casación por violación o falsa aplicación de los contratos y acuerdos colectivos nacionales del trabajo. Es decir, su violación o falsa aplicación es considerada una violación o falsa aplicación de normas de derecho, lo que permite el recurso de casación ${ }^{94}$.

La Ley de Huelga en servicios esenciales ( $N^{\circ} 146$ de 1990 modificada por la Ley № 83 de 2000), delegó en la contratación colectiva la determinación de las prestaciones indispensables para resguardar los intereses de terceros ${ }^{95}$. Los otros aspectos del derecho de huelga están desregulados, salvo lo dispuesto

\footnotetext{
${ }^{88}$ D'ANTONA (2000), pp. 411 a 413. Más allá de los clásicos efectos normativo y obligatorio del contrato colectivo, la doctrina italiana habla de "eficacia constitutiva" cuando el legislador, por ejemplo, establece que la contratación colectiva podrá autorizar al empleador a realizar contrataciones futuras con figuras o tipología prohibidas o restringidas por ley. Es decir, si por ejemplo, el legislador estatuye que hasta el $20 \%$ de la plantilla de una empresa puede estar contratada a plazo y no indefinidamente, en tiempos de crisis se autoriza a superar dicho tope de $20 \%$ siempre y cuando se negocie y los contratos colectivos lo contemplen en forma expresa. Se trata de una verdadera flexibilidad negociada en donde la negociación colectiva incide en la legitimidad para celebra figuras contractuales precarias o flexibles. Véase Gamonal (2011), p. 312. Otra denominación es también "función o contratación gestional". Véase Corso (2017), p. 149.

${ }^{89}$ D'ANTONA (2000), p. 413.

90 D'ANTONA (2000), pp. 411 a 413.

${ }^{91}$ CORSO (2017), p. 170.

${ }^{92}$ CORSO (2017), p. 170.

${ }^{93}$ D'ANTONA (2000), p. 403.

${ }^{94}$ Curzio (2014), pp. 753-765.

${ }^{95}$ Corso (2017), p. 171 y LatTari (2016), pp. 60 y 61.
} 
en el ya citado artículo 40 de la Constitución italiana. Con todo, la doctrina y la jurisprudencia entienden que esta norma constitucional es inmediatamente aplicable ante falta de ley, y que la huelga constituye una reafirmación de la libertad sindical del artículo 39, y que la participación en huelgas exime al trabajador de prestar sus servicios y al empleador de pagar la remuneración, no constituyendo un incumplimiento contractual ${ }^{96}$.

Dado lo anterior, se fue generando una compenetración profunda entre el ordenamiento estatal y el intersindical, en base a una cooperación cada vez más estrecha entre el Estado y los actores sociales ${ }^{97}$.

Por su parte, la jurisprudencia también ha ampliado los efectos del contrato colectivo de derecho común. Más allá de la aplicación espontánea de las condiciones laborales de la contratación colectiva que realizan algunos empleadores, en forma expresa (contrato individual) o tácita, la jurisprudencia ha extendido indirectamente los contratos colectivos interpretando el artículo 36 de la Constitución italiana, que reconoce a los trabajadores el derecho a una retribución proporcionada a la cantidad y calidad de su trabajo y suficiente, en cualquier caso, para asegurar a su familia y a él una existencia libre y digna. De esta forma se ha entendido que la retribución justa alude a las condiciones económicas mínimas que considera la contratación colectiva sectorial o de categoría ${ }^{98}$.

También se ha discutido la eficacia erga omnes de los contratos colectivos a nivel de empresa, sobre todo en aquellos gestionales en las situaciones de crisis. Algunos estiman que son de aplicación general en la empresa, dado que los intereses gestionados en el acuerdo son indivisibles. Otros, por el contrario, consideran que no puede prescindirse ni en estos casos, del principio del voluntarismo del sistema sindical italiano ${ }^{99}$. No obstante, desde el 2014 con el Texto Único de la Representación, acordado por las multisindicales de sindicatos y empleadores, se determina que los contratos colectivos de empresa son aplicables a todos los trabajadores de la misma ${ }^{100}$.

En cuanto a la relación entre contrato colectivo y contrato individual, la jurisprudencia postconstitucional aplicó el artículo 2077 del Código Civil italiano, una norma corporativa del régimen de Mussolini, para asegurar la eficacia real del contrato colectivo de derecho común, en el sentido de que el contrato

\footnotetext{
96 LATTARI (2016), p. 59.

97 D'ANTONA (2000), p. 403.

98 Corso (2017), pp. 172 y 173.

99 Corso (2017), pp. 174 y 175.

100 CORSO (2017), p. 175.
} 
individual no podía derogar el régimen colectivo. Esta situación anómala, que aplicaba una norma heredada de un sistema distinto (corporativismo italiano) al contrato colectivo de derecho privado, fue subsanada en 1973 con la reforma al artículo 2113 del Código Civil, por la Ley № 533 de 1973, estatuyéndose que serán inválidas la renuncia y transacciones de las normas inderogables de rango legal o de los contratos o acuerdos colectivos ${ }^{101}$. Obviamente, las derogaciones a favor del trabajador (in melius) son admitidas plenamente ${ }^{102}$.

Las relaciones entre el ordenamiento estatal y el intersindical, desde el año 2011, no han sido del todo pacíficas, produciéndose algunas fisuras o tensiones importantes. Sin embargo, para tener una perspectiva completa primero veremos cómo opera este Ordenamiento Intersindical desde una perspectiva autónoma, para luego ver sus fisuras internas y las externas generadas por las últimas leyes desde el año 2011.

Los principales tipos de contrato colectivo en el Ordenamiento Intersindical son el contrato colectivo nacional de categoría y el contrato colectivo a nivel de empresa, sin perjuicio de que también existe ocasionalmente negociación colectiva territorial de sindicatos provinciales o regionales ${ }^{103}$. Estos instrumentos se sujetan a mecanismos de coordinación de carácter intersindical, estableciendo una jerarquía superior al contrato nacional de categoría y un sistema de cláusulas de reenvío desde estos al contrato de empresa sobre las materias a regular por este último ${ }^{104}$.

No estamos hablando de una eficacia obligatoria estatal, sino de las reglas a las que voluntariamente se someten los actores sociales. Es por ello que, desde fines de la década de los sesenta del siglo pasado, se observan contratos colectivos a nivel de empresa o territorial que no se sujetan a las reglas del contrato nacional de categoría ${ }^{105}$. Y los criterios para resolver el concurso entre contratos no son pacíficos, aunque ha predominado en la jurisprudencia el criterio de

\footnotetext{
101 Corso (2017), pp. 176 y 177.

102 Corso (2017), p. 177.

103 Corso (2017), p. 177 y Santoro-Passarelli (2015), nota 9 en p. 7.

También existe contratación colectiva intersectorial, aunque no es común. Por ejemplo, el 19 de diciembre de 2016 fue suscrito un contrato colectivo intersectorial para los trabajadores del sector Comercio, del Terciario, de la Distribución, de Servicios, y Turismo. Véase Ballistreri (2017), pp. 762 a 768 .

104 Corso (2017), pp. 177 y 178, y Santoro-Passarelli (2015), p. 3.

Asimismo, dentro de la misma categoría o rama puede haber más de un contrato nacional.

105 Imberti (2013), p. 269, y SAntoro-Passarelli (2015), p. 4.
} 
especialidad del contrato de empresa, que es más cercano a los intereses de los beneficiarios ${ }^{106}$.

Desde los sesenta, en el período de boom económico, la contratación articulada dentro del Ordenamiento Intersindical (contrato colectivo nacional de categoría jerárquicamente superior al de empresa, que además delimita la competencia de este último por medio de cláusulas de reenvío $)^{107}$ fue siempre en alza, es decir el contrato colectivo de empresa elevaba los mínimos sectoriales del nacional de categoría ${ }^{108}$. Y luego muchas de las mejoras eran incorporadas al contrato nacional, extendiéndose de esta forma a más trabajadores ${ }^{109}$. Los empleadores no aceptaron en principio el sistema de contratación articulado, aunque luego éste logró consolidarse asegurando al sector empresarial cláusulas de tregua sindical mientras rigieran los contratos colectivos ${ }^{110}$. A fines de los sesenta se observa el fin de la contratación articulada, predominando nuevamente la centralización por medio de la contratación colectiva nacional de categoría, sin perjuicio de la existencia de algunos contratos colectivos de nivel empresarial, en lo que se denominó contratación desvinculada, que, en todo caso, alzaba los contenidos nacionales. Era un sistema articulado en dos niveles pero no coordinado ${ }^{111}$.

Con la llegada de la recesión económica desde la crisis petrolera de los setenta, se observa una importante fisura interna en el Ordenamiento Intersindical, dado que muchos contratos colectivos de empresa rebajan los mínimos del colectivo nacional de categoría ${ }^{112}$.

El Ordenamiento Intersindical ha mantenido una cierta coordinación por medio de los Acuerdos Interconfederales intentando delimitar las competencias entre el contrato nacional de categoría y el de empresa. No obstante, se observan fisuras y muchas veces los contratos a nivel empresarial son suscritos por organizaciones sindicales que no pertenecen a las confederaciones estipulantes del contrato nacional de categoría ${ }^{113}$.

\footnotetext{
106 SANtoro-Passarelli (2015), p. 6.

108 SAntoro-Passarelli (2015), p. 3.

109 Santoro-Passarelli (2015), p. 3.

110 Santoro-Passarelli (2015), p. 4.

111 Santoro-Passarelli (2015), pp. 4 y 5.

112 Santoro-Passarelli (2015), p. 5.

113 Santoro-Passarelli (2015), p. 6.
}

107 En julio de 1962 las federaciones sindicales de la categoría metalmecánica firmaron junto a las organizaciones de trabajadores de empresas del Estado, un acuerdo que establecía un nuevo sistema contractual colectivo articulado en base a dos niveles (nacional de categoría y empresa), y que luego fue adoptado en distintos contratos nacionales de categoría. Véase SANTORO-PASSARELLI (2015), nota 1 en p. 3. 
Con el Acuerdo Interconfederal de 1993 se intentó nuevamente estatuir un sistema articulado y coordinado en dos niveles, a saber, nacional de categoría y de empresa ${ }^{114}$. El primero establecía la competencia del contrato de empresa, en materias no reguladas expresamente por el contrato colectivo nacional de categoría. Este acuerdo se mantuvo vigente muchos años y en 2009 hubo un nuevo acuerdo interconfederal que no fue suscrito por una de las principales multisindicales de trabajadores, la CGIL, el cual fue poco efectivo considerando además la crisis económica del 2008 que implicó reducción de costos empresariales.

Más recientemente la tres multisindicales italianas han suscrito tres Acuerdos Interconfederales en 2011, 2013 y 2014, y este último aglutina los anteriores y es denominado Texto Único de Representatividad (en adelante Texto Único), para reafirmar el principio de unidad de acción sindical115 ante el caso Fiat, donde la emblemática fábrica italiana se descolgó del contrato colectivo nacional metalmecánico y firmó contratos colectivos de empresa con menores derechos. En efecto, desde el 2010 la empresa Fiat firmó varios contratos colectivos a nivel de empresa (en Pomigliano, Mirafiori y Ex Bertone di Grugliasco) derogando los mínimos nacionales de categoría. Este descuelgue puso en evidencia algunos puntos críticos del sistema intersindical italiano, a saber, la derogabilidad in peius del contrato nacional por parte del contrato colectivo de empresa, la falta o carencia de reglas idóneas para disciplinar el disenso entre sindicatos y niveles contractuales, y la eficacia subjetiva de los contratos colectivos y su exigibilidad ${ }^{116}$.

Primero el acuerdo del 2011 y el ya mencionado Texto Único del 2014 permiten derogaciones de los mínimos nacionales de categoría por parte del contrato colectivo de empresa, según el reenvío expreso que hagan los contratos colectivos nacionales ${ }^{117}$. Se trata de una "derogación controlada" en que reconoce la jerarquía superior del nivel nacional respecto del de empresa ${ }^{118}$. En todo caso, pocos contratos nacionales han previsto materias susceptibles de derogar a nivel de contratación colectiva de empresa, prefiriendo enumerar las materias inderogables y contemplando la intervención de los sindicatos territoriales para el caso de ser necesaria alguna derogación a nivel de empresa ${ }^{119}$.

\footnotetext{
114 Santoro-Passarelli (2015), p. 7.

115 Santoro-Passarelli (2015), p. 7.

116 Giugni (2015), pp. 179 a 182.

117 Santoro-Passarelli (2015), pp. 8 y 9.

118 Santoro-Passarelli (2015), p. 9.

119 Santoro-Passarelli (2015), p. 10.
} 
El Texto Único contempla, además, un régimen transitorio en caso de que el contrato nacional de categoría no contemple la posibilidad de derogaciones a nivel de contratación colectiva de empresa (y mientras no lo haga). En estos casos, las derogaciones sólo son admitidas para ciertas materias, a saber, prestación laborativa, horarios y organización del trabajo, con el solo objetivo de gestionar situaciones de crisis o ante inversiones significativas. En estos casos, el contrato colectivo de empresa no sólo debe ser suscrito por los representantes de la misma sino también por los sindicatos territoriales ${ }^{120}$.

El Texto Único busca dar certeza a los actores sociales y al funcionamiento del Ordenamiento Intersindical. Con todo, muchas empresas de pequeñas dimensiones quedan fuera de este acuerdo (no adhieren a ninguna asociación empresarial) ${ }^{121}$, y la doctrina hace presente la necesidad de una norma heterónoma estatal que establezca un sistema de representación aunque existen dudas y temores de que dicha intervención intente superar y eclipsar el Ordenamiento Intersindical, como ha ocurrido desde el $2011^{122}$.

En este punto de la exposición, ya podemos explicar las fisuras externas entre el derecho estatal y el Ordenamiento Intersindical. En efecto, durante el mandato de Berlusconi el artículo $8^{\circ}$ del decreto Ley № 138 de 2011, convertido en Ley $\mathrm{N}^{\circ} 148$ del mismo año, intentó desarticular el acuerdo interconfederal del $2011^{123}$, dado que autoriza directamente a los contratos colectivos de empresa (denominados de proximidad) y de nivel territorial a pactar "acuerdos específicos" con fines sumamente amplios: para incrementar la ocupación, para elevar la calidad de los contratos de trabajo, para adoptar formas de participación de los trabajadores, para visibilizar el trabajo informal, para incrementar la competitividad y los salarios, para gestionar la crisis de las empresas y la crisis ocupacional, y para fomentar inversiones y el inicio de nuevas actividades. Estos acuerdos específicos pueden derogar los mínimos legales y los mínimos nacionales de categoría ${ }^{124}$ y pueden recaer en la regulación de los materiales pertinentes la organización del trabajo y la producción con referencia a:

- Elementos audiovisuales e introducción de nuevas tecnologías,

- A las tareas del trabajador, su clasificación y encuadramiento laboral,

\footnotetext{
120 Santoro-Passarelli (2015), p. 10.

121 CARRIERI (2014), p. 559.

122 Carrieri (2014), pp. 559 a 561.

${ }^{123}$ El Gobierno de Berlusconi explicó que esta norma había sido introducida por exigencia de la Unión Europea. Con todo, la doctrina ha sido muy escéptica respecto de esta explicación. Véase Dı StAsI (2014), p. 134, y Arrigo (2013), pp. 55 y 56.

${ }^{124}$ CORSO (2017), p. 181.
} 
- A los contratos a plazo, de horario reducido, modulado o flexible, a los regímenes de solidaridad en el caso de los subcontratistas y en el caso del trabajo suministrado,

- A la jornada de trabajo, y

- A las modalidades de contratación y al régimen de la relación de trabajo, comprendidas las relaciones de colaboración coordinada y continuativas y las partidas IVA, a la transformación y conversión de los contratos de trabajo y a las consecuencias del término del contrato, salvo los casos de despido discriminatorio, del despido de la trabajadora por casarse o embarazada durante sus permisos de maternidad y hasta que el bebé cumpla un año de vida, o del despido causado por los permisos parentales o de enfermedad del menor por parte de la trabajadora o el trabajador, y por el despido en caso de adopción.

Después de esta amplísima autorización derogatoria, el artículo $8^{\circ}$ que comentamos precisa que, sin perjuicio de la Constitución y de las limitaciones derivadas de la legislación comunitaria y de los convenios internacionales del trabajo, los acuerdos específicos establecidos anteriormente, se aplicarán también cuando deroguen las disposiciones legales y las reglamentaciones pertinentes de los contratos colectivos nacionales de trabajo ${ }^{125}$.

Además, esta norma establece que los efectos de estos contratos colectivos y sus acuerdos específicos tienen eficacia respecto de todos los trabajadores interesados, conformándose una "eficacia erga omnes" de este tipo de instrumentos ${ }^{126}$.

Esta norma del artículo $8^{\circ}$ de la Ley $N^{\circ} 148$ del 2011, implicaba un quiebre con el principio de inderogabilidad de la ley y del contrato colectivo, alteraba la jerarquía entre contratos colectivos de distinto nivel y favorecía la competencia entre el contrato nacional y el de empresa con miras a superar el primero ${ }^{127}$. La norma estaba inserta en una ley destinada a contener el déficit público italiano y que nada tenía que ver con la temática de las relaciones industriales y menos con consagrar la posibilidad de derogar enteramente el derecho del trabajo por vía de los contratos colectivos territoriales o empresariales ${ }^{128}$. Por otro lado, la doctrina ha señalado la probable inconstitucionalidad de esta norma, por no someterse a los requisitos contemplados en el artículo 39 de la Constitución

\footnotetext{
125 Santoro-Passarelli (2015), p. 13.

126 GiUgni (2015), p. 207.

127 SANTORO-PASSARell (2015), p. 15.

${ }^{128}$ MariucCi (2011), p. 459.
} 
italiana ${ }^{129}$. Además, esta norma legal lo que buscaba era legitimar la contratación empresarial de la FIAT y su descuelgue del sistema nacional de categoría ${ }^{130}$.

Esta delegación legal en blanco y de amplio espectro fue una especie de homicidio frustrado del Ordenamiento Intersindical' ${ }^{131}$. En efecto, al poco tiempo de dictada esta ley, el 21 de septiembre de 2011, las multisindicales italianas declararon formalmente que no aplicarían esta norma estatal ${ }^{132}$. Y en la actualidad el Ordenamiento Intersindical está regido por el Texto Único 2014, adoptado por los actores sociales y con el sistema de derogación controlado que ya comentamos. Este acuerdo interconfederal no hace referencia alguna al artículo $8^{\circ}$ de la Ley $N^{\circ} 148$ del $2011^{133}$, ya que las tres grandes confederaciones para evitar el efecto demoledor de esta norma, se comprometieron a no aplicarla en ningún caso ${ }^{134}$.

Los Gobiernos de centro derecha han intentado debilitar a las tres confederaciones enfatizando sus distintas culturas y sensibilidades políticas ${ }^{135}$, produciéndose varios casos de acuerdos separados entre la CISL y la UIL y excluyendo a la CGIL. Y el Gobierno de Matteo Renzi, del Partido Democrático, continuó por este camino ${ }^{136}$. La legislación posterior del ordenamiento estatal ha mantenido esta línea autorizando al contrato colectivo de empresa (de proximidad) a derogar in peius las normas legales y las reglas emanadas de los contratos colectivos nacionales de categoría. En este sentido, opera la Ley $N^{\circ} 183$ de 2014, más conocida como Jobs Act ${ }^{137}$.

No obstante, los actores sociales a través del Ordenamiento Intersindical insisten en regular en forma autónoma del Estado el sistema de relaciones industriales italiano, por medio de los acuerdos interconfederales ya citados desde el 2011 hasta el Texto Único del 2014. Por su intermedio, las tres grandes Confederaciones han reordenado la contratación colectiva, comprendiendo

\footnotetext{
129 SCARPoni (2016), pp. 9 y 10; GIUGNI (2015), pp. 201 y 211; LeCCESE (2012), pp. 479-525, y MariuCCI (2011), p. 459.

130 MARIUCCI (2011), pp. 462 y 463.

131 La doctrina habló de deconstrucción y ruptura del sistema, de cambio en las jerarquías de las fuentes del derecho, de derrocamiento de las relaciones entre fuentes, y de privatización del contrato colectivo nacional de categoría. Véase Dı StASI (2014), pp. 133 a 135 y Romeo (2015), pp. 7 y 8.

132 Santoro-Passarelli (2015), nota 10 en p. 7.

133 ROMEO (2015), p. 16.

134 ARRIGO (2013), p. 57.

135 Gian Primo Cella citado en Giugni (2015), p. 47.

136 Pallini (2016), p. 4.

137 Santoro-Passarelli (2015), p. 16.
} 
elementos de desconcentración controlada a nivel de empresa, intentando legitimar su actuar por medio de reglas de representación adecuadas para la contratación nacional de categoría, afirmando, por otra parte, la eficacia de los contratos de empresa, garantizando a las empresas la neutralización del disenso individual y colectivo e integrando la aplicación de los contratos colectivos pactados ${ }^{138}$.

Por otro lado, y como expresión de una política pragmática, desde mediados de los setenta constituye una práctica de los sindicatos a nivel de empresa suscribir contratos colectivos que en casos de crisis económica rebajan los estándares del contrato colectivo nacional de categoría ${ }^{139}$. Y también encontramos los denominados "contratos colectivos piratas" suscritos por sindicatos minoritarios o no adherentes a las mayores confederaciones y que rebajan estándares de categoría ${ }^{140}$. Por esta vía se ha buscado aumentar la competitividad y atraer nuevas inversiones. Por tanto, lo realizado por las tres confederaciones desde el 2011 ha sido el intento de regular y formalizar un sistema de derogación a nivel de empresa que sea controlado a nivel confederal.

Esta opción es absolutamente distinta que la del legislador estatal, que ha intentado conceder derogaciones en blanco a la contratación colectiva de empresa, tanto del estándar nacional colectivo como de los mínimos legales.

Otros han destacado que las derogaciones a nivel de contrato colectivo de empresa se hacen pero no se dicen. Es decir, dentro del Ordenamiento Intersindical hay una verdadera contratación paralela, silenciosa y colaborativa, de orden pragmático y desideologizado, donde se hacen renuncias al estándar de categoría y se comprenden algunas de las materias del artículo $8^{\circ}$ de la Ley № 148 de 2011, pero sin jamás mencionar este respecto del ordenamiento estatal $^{141}$. Consultados algunos actores sindicalistas del sistema, se hace presente que la contratación colectiva de empresa desde la crisis económica de los setenta realiza acuerdos derogatorios como los descritos. Pero se trata de momentos de crisis y de casos de excepción, y en ese contexto y en un momento como el actual, es lógico no mencionar la norma legal dado que se trata de una excepción que no debe ser elevada al carácter de principio ${ }^{142}$.

\footnotetext{
138 Bellardi (2014), p. 740.

139 Bellardi (2014), p. 744.

140 D'ANTONA (2000), p. 410.

141 IMBERTI (2013), pp. 268 y 269.

142 IMBERTI (2013), pp. 268 y 269.

Los sindicalistas aseguran también que es mejor que los acuerdos derogatorios sean directamente negociados colectivamente a nivel de empresa, de forma que los trabajadores estén conscientes de los costos y beneficios del acuerdo. Los empleadores, por otro lado, prefieren la certeza de un contrato
} 
Este sistema flexible pero controlado desde el nivel confederal (no en blanco) permite que cuando mejoran las condiciones económicas se encuentren vigentes los mecanismos del Ordenamiento Intersindical para que los trabajadores puedan exigir mejores beneficios y gozar de los beneficios del crecimiento, al igual como ya ha ocurrido en los contratos colectivos gestionales ${ }^{143}$.

Como balance, la situación es de incerteza dado que nos encontramos ante regulaciones contradictorias de dos ordenamientos en pugna, por un lado el Estatal y por otro el Intersindical ${ }^{144}$. Se habla de una crisis radical, fisiológica y sistémica del sistema italiano ${ }^{145}$. Otros describen el sistema italiano como un régimen caótico ${ }^{146}$. Los escenarios a futuro son dispares, a saber: (1) se puede mantener el status quo con una gobernanza multinivel intersindical con un alto grado de coordinación horizontal y con un bajo coeficiente de integración vertical, es decir escasa efectividad (contratación pirata) y escasa certeza de las reglas $^{147}$. O puede deslizarse el sistema hacia un (2) "neoliberalismo contractual", donde se vacíe cada vez más la contratación colectiva nacional de categoría con un claro desequilibrio en favor de la negociación de empresa ${ }^{148}$. $\mathrm{O}$, finalmente, (3) que se consagre una perspectiva "neocorporativista" donde el legislador regule el fenómeno sindical al tenor del artículo 39 de la Constitución italiana ${ }^{149}$.

Parte de la doctrina considera que el derecho sindical italiano, luego del terremoto institucional del artículo $8^{\circ}$ de la Ley $N^{\circ} 148$ del 2011, ha entrado en una nueva fase de no retorno, de primacía de la ley sobre la contratación colectiva $^{150}$.

Otros enfatizan la solidez del Ordenamiento Intersindical frente al derecho estatal, y destacan que el Texto Único ha tomado un claro camino de construir y consolidar este ordenamiento ${ }^{151}$. En el documento "Moderno sistema de re-

colectivo empresarial, sin mencionar el aludido art. $8^{\circ}$ de la Ley $^{\circ} 148$ de 2011, el cual pudiera ser impugnado dado que puede ser estimado inconstitucional. Véase IMBERTI (2013), pp. 266 y 267.

${ }^{143}$ El reenvío a la negociación colectiva en Italia, permitiendo la co-gestión del mercado de trabajo desde los ochenta, permitió evitar que el momento de crisis se resolviera en una mera reducción de los niveles de tutela de los trabajadores. Véase OlivierI (2014), p. 346.

\footnotetext{
144 Romeo (2015), p. 17.

145 ROMEO (2015), p. 24.

146 Pallini (2016), p. 4.

147 Tomassetti (2015), p. 3.

148 TOMASSETTI (2015), p. 4.

149 Tomassetti (2015), p. 6.

150 Romeo (2015), pp. 28 y 29.

151 MAResca (2014), pp. 563 y ss.
} 
laciones industriales. Por un modelo de desarrollo fundado en la innovación y en la calidad del trabajo", de enero de 2016, las tres centrales sindicales han confirmado nuevamente la unidad sindical, la vigencia del Texto Único y hacen un Ilamado a implementar legalmente el artículo 39 de la Constitución para conceder eficacia erga omnes a los contratos colectivos nacionales en materia de ingreso mínimo ${ }^{152}$.

Estimamos que el Ordenamiento Intersindical se mantiene operativo aunque con las diversas fisuras internas y externas ya descritas, configurándose como un Ordenamiento Intersindical fragmentado. Quizás el mayor problema, según lo explicado, es la carencia de un sistema de representación estatal heteróno$\mathrm{mo}^{153}$. Por otra parte, dada la constante crisis económica italiana, el legislador de los últimos años ha fomentado unilateralmente y con delegaciones amplias el descuelgue del segundo nivel de negociación (de proximidad) por medio de la contratación colectiva de nivel de empresa.

Lo anterior, sin perjuicio de destacar el éxito y gran atractivo de la reconstrucción de Giugni mediante la teoría del Ordenamiento Intersindical, como contexto explicativo del sistema italiano y de los sistemas regulatorios privados de la esfera social ${ }^{154}$. En palabras de Giovanni Pino el Ordenamiento Intersindical: "constituye sin duda una suerte de manifiesto de refundación del derecho sindical y del trabajo, además de ser un punto de referencia imprescindible para los estudios juslaboralistas y para la política del trabajo"155.

152 SCARPONI (2016), pp. 28 y 29.

${ }^{153}$ La plena exigibilidad contractual colectiva sólo puede ser garantizada por una intervención legislativa según Tomassetti. Véase TOMASSETt (2015), p. 8. El voluntarismo del ordenamiento intersindical deja fuera a todas aquellas empresas que no pertenecen a las organizaciones empresariales y a numerosas pequeñas empresas sin presencia sindical. Por ello, es vista positivamente la posibilidad de una intervención al estilo del derecho alemán, como "valor adjunto" que permite ampliar la representación de los trabajadores. Véase CARRIERI y PIRRO (2016), p. 88.

Para muchos el Texto Único no requiere de ley alguna para su eficacia. Para otros, es necesario una intervención legislativa y los debates y las propuestas de la doctrina son variados y de distinto alcance. Claramente no existe acuerdo entre los académicos en esta materia. Véase SCARPONI (2016), pp. 20 a 28. Otra corriente importante es la sigue postulando la abstención legislativa, sobre todo por la dificultad de legislar dando cumplimiento al art. 39 de la Constitución. Véase Carrieri y PIRRO (2016), p. 85.

154 Sciarra (2013), p. 66; Ferrari (2012), pp. 195 a 199; Sciarra (2010), pp. 117-123; Ghera (2007), pp. 265-272, y CeLLA (2007), pp. 273-291.

Desde una perspectiva académica Romagnoli destaca la idoneidad de Gıugnı para demoler el identikit del jurista como técnico del derecho y rediseñar la labor académica con la finalidad de estatuir un contacto simbiótico permanente con la dimensión política sin por ello dejar de lado el pensamiento científico. Este proceso de cambio antropológico cultural se vio favorecido por su elección de no ejercer la profesión de abogado. Véase Romagnol (2007), p. 324.

155 PINO (2016), p. 32. 


\section{Conclusiones: autonomía y heteronomía en los sistemas de negociación}

Estudiados los dos casos propuestos en la introducción, el uruguayo y el italiano, podemos ofrecer algunas conclusiones de interés para el derecho social latinoamericano, en relación a la cuestión sobre la autonomía y la ley.

Desde ya, debemos precisar que ambos sistemas son distintos aunque se los haya considerados como de abstención legislativa. En efecto, el caso uruguayo ha dependido de la Ley de Consejos de Salarios, y su actual éxito se ha basado en la obligatoriedad de la convocatoria de los mismos establecido por las recientes enmiendas legales que hemos comentado. Además, la doctrina y la jurisprudencia han respaldado el desarrollo sindical, por ejemplo, interpretando ampliamente el derecho de huelga mencionado en la Constitución uruguaya.

Por el contrario, el caso italiano ha sido más autónomo e independiente del Estado, de lo que da cuenta la teoría misma del Ordenamiento Intersindical. Sin embargo, esta autonomía ha dependido de algunas normas estatales, desde ya la Constitución italiana ha sido clave, sobre todo el artículo 40 sobre derecho de huelga y su interpretación jurisprudencial. Y la reforma del año 1973 al artículo 2113 del Código Civil ha sido importante para enfatizar la superioridad jerárquica de estándar colectivo sobre el contrato individual de trabajo.

En consecuencia, más allá de las modalidades nacionales y de los diferentes contextos, pareciera difícil que un sistema sindical por autónomo que sea pueda desarrollarse sin algún tipo de auxilio estatal. Y esto pareciera lógico si se considera que el ordenamiento estatal tenderá a ser siempre más efectivo, dado que monopoliza el uso de la fuerza. Dicha efectividad en un Estado social y democrático de derecho, debemos entenderla como directamente relacionada con la tutela de los derecho fundamentales, y para el caso de estudio de este trabajo, de la protección de la libertad sindical ${ }^{156}$.

Por lo anterior, podemos deducir que, en aquellos sistemas que se caracterizan por un abstencionismo legislativo, entendido como aquellos en que el legislador interviene en forma minimalista en las relaciones sindicales, no debe menospreciarse este "minimalismo" estatal, siempre clave cuando se estudia el referido sistema. Esta protección mínima debe ser asegurada a través del Estado y va a delimitar la extensión de los instrumentos colectivos en caso de mayor o menor autonomía.

Respecto del otro sistema de abstencionismo, el británico hasta fines de los setenta del siglo pasado, Ruth Dukes hace presente la importancia

156 Gamonal (2011), pp. 62 y ss. 
del soporte estatal de la autonomía colectiva incluso en esquemas tan de lassez-faire como Gran Bretaña en la primera mitad del siglo $X X^{157}$. Y por muy autónomo que fuera el sistema británico, cuando el Gobierno de Thatcher quiso destruir el movimiento sindical con leyes adversas logró hacerlo apoyada por la crisis económica de los ochenta. Como señala Hugh Collins, la lección que nos enseña esta historia es que el derecho colectivo del trabajo sólo puede sobrevivir con leyes fuertes que lo sostengan ${ }^{158}$.

Así las cosas ¿Cómo se pueden coordinar la ley y las fuentes de derecho estatal con la autonomía de los sindicatos? La ley debe ser de sostén y respetar la autonomía sindical. Para ello, debe ser una ley que consagre derechos pero que su operativa quede entregada a la autonomía de los actores sociales. Es decir, una ley que consagre el derecho de sindicación, la negociación colectiva multinivel y un amplio derecho de huelga. Todo esto en pocos artículos, y sin que el legislador determine por sí mismo las alternativas y modalidades. Ejemplo de lo anterior puede ser el actual caso uruguayo. Una ley de sostén debiera seguir muy de cerca lo dispuesto en los Convenios 87 y 98 de la OIT.

En los países de América Latina la no intervención o neutralidad estatal implica un apoyo silencioso a los empleadores. Nuevamente un buen ejemplo es el caso de Uruguay, cuando el Estado decidió no convocar más a los Consejos de Salarios ${ }^{159}$.

Y obviamente la ultra reglamentación que caracteriza a nuestros países tampoco fomenta un sistema sindical libre y autónomo. Más bien lo asfixia ${ }^{160}$.

Finalizaremos recordando las sabias palabras de Mario de la Cueva, quien hablaba de la visión triangular del derecho colectivo del trabajo ${ }^{161}$ : "La doctrina puede representarse gráficamente como un triángulo equilátero, cuyos ángulos, todos idénticos en graduación, serían el sindicato, la negociación y contratación colectiva y la huelga, de tal suerte que ninguna de las tres figuras de la trilogía podría faltar, porque desaparecería el triángulo"162.

Como explicaba De la Cueva esta trilogía indisociable entre sindicato, negociación y huelga buscaba enfatizar, en el caso Latinoamericano, el olvido

\footnotetext{
157 DukEs (2014), pp. 89 a 91.

${ }^{158}$ Coluins (2011), p. 139.

159 RASO (2014), p. 421.

160 Gamonal (2011), pp. 30 y ss.

161 De la Cueva (1994), pp. 675 y ss.

162 De la Cueva (1994), p. 679.
} 
de muchos legisladores por establecer un real derecho de huelga ${ }^{163}$. Es por ello, que mediante esta visión triangular quiso destacar la esencialidad del derecho de huelga junto a los otros dos elementos del triángulo.

Nosotros podemos agregar y volver a enfatizar, en base a los casos estudiados, que los tres elementos del triángulo son realmente vitales. Desde ya la huelga como enfatiza De la Cueva, pero también el sistema negociador como demuestra el caso uruguayo y también la representatividad sindical, al tenor de las actuales carencias y fisuras internas del Ordenamiento Intersindical italiano. Un triángulo equilátero implica per se una mayor y mejor extensión de los beneficios obtenidos por la negociación colectiva.

\section{BiBLIOGRAFíA CITADA}

AA.VV. (2010): Cuarenta Estudios sobre la Nueva Legislación Laboral Uruguaya, (XXXV aniversario del Grupo de los Miércoles, Montevideo, Fundación de Cultura Universitaria).

ARRIGO, Gianni (2013): "Apuntes críticos sobre la reciente reforma del mercado de trabajo italiano", en: Revista de Trabajo, (№ 9, Número 11), pp. 55-73.

Ballistrerl, Maurizio (2017): "La Contrattazione Collettiva Intersettoriale", en: Diritto \& Pratica del Lavoro (13), pp. 762-768.

Barbagelata, Héctor-Hugo; Rosenbaum Rímolo, Jorge, y Garmendia Arigón, Mario (1998): El Contenido de los Convenios Colectivos, (Montevideo, Fundación de Cultura Universitaria).

Baylos Grau, Antonio (1991); Derecho del Trabajo: modelo para armar, (Madrid, Trotta).

BELLARDI, Lauralba (2014): "La recente reforma della struttura contrattuale: profili critici e incoerenze", en: Giornale di Diritto del Lavoro e di Relazioni Industriali, (No 144, anno XXXVI), pp. 739-752.

BogG, Alan (2016): "Beyond Neo-Liberalism: The Trade Union Act 2016 and the Authoritarian State", en: Industrial Law Journal 45 (3), pp. 299-336.

Carrieri, Mimmo y Pirro, Fabrizio (2016): Relazioni Industriali, (Milán, Egea).

CARRIERI, Mimmo (2014): “La lunga fluoriuscita dall'incerta rappresentanza: un approdo finalmente solido?", en: Giornale di Diritto del Lavoro e di Relazioni Industriali, (No 143, anno XXXVI, 3), pp. 549-562.

\footnotetext{
163 De la Cueva (1994), pp. 675 a 679.
} 
Carrillo Calle, Martín (2015): "La mejora de la cobertura de la negociación colectiva en América Latina", en: Revista Latinoamericana de Derecho Social, (No 21), pp. 3-29.

Carincl, Franco; De Luca Tamajo, Rafaelle; Tosi, Paolo y Treu, Tiziano (1994): Diritto Sindacale, (Volumen 1, Turín, UTET).

CAstello, Alejandro (2010): El derecho de huelga. Principales características del modelo uruguayo, (II Encuentro Chileno-Uruguayo, Sociedad Chilena de Derecho del Trabajo y de la Seguridad Social y Sociedad Uruguaya de Derecho del Trabajo y de la Seguridad Social, Santiago, noviembre de 2010, inédito).

Cella, Gian Primo (2007): "Il camino del pluralismo: Giugni e le Relazioni Industriali", en: Giornale di Diritto del Lavoro e di Relazioni Industriali, (No 114, anno XXIX, 2), pp. 273-291.

Coluins, Hugh (2011): "Theories of Rights as Justifications for Labour Law", en: The Idea of Labour Law (editado por Guy Davidov y Brian Langille, Oxford, Oxford University Press), pp. 137-155.

Corso, Fulvio (2017): II Diritto Sindacale, (3ª edición, Turín, G. Giappichelli Editore).

Curzıo, Pietro (2014): "Nomofilachia e Autonomia Collettiva", en: Giornale di Diritto del Lavoro e di Relazioni Industriali, ( $N^{\circ} 144$, anno XXXVI, 4), pp. 753-765.

D'antona, Massimo (2000): Il Quarto Comma dell'Art. 39 della Costituzione, Oggi, en: Massimo D' Antona Opere, Volumen segundo (al cuidado de Bruno Caruso y Silvana Sciarra, Milán, Giuffrè), pp. 399-438.

Davies, Paul y Freedland, Mark (1987): "Introducción de los editores de la tercera versión inglesa", en: Otto Kahn-Freund, Trabajo y Derecho, (Madrid, Ministerio del Trabajo y de la Seguridad Social), pp. 31-43.

De la Cueva, Mario (1994): El humanismo jurídico de Mario de la Cueva, (Recopilación de escritos de Mario de la Cueva realizada por Ana Luisa Izquierdo y de la Cueva, México, Fondo de Cultura Económica).

Dı STASI, Antonio (2014): “Questioni problematiche sulle fonti del Diritto del lavoro in Italia", en: Derecho a la Negociación Colectiva. Liber Amicorum Profesor Antonio Ojeda Avilés, (Juan Gorelli Coordinador, Sevilla, Consejo Andaluz de Relaciones Laborales), pp. 129-137.

DUKES, Ruth (2014): The Labour Constitution. The enduring idea of Labour Law, (Oxford, Oxford University Press). 
Durán, Gonzalo (2015): Negociación Colectiva por sector económico, productividad, empleo y desigualdad. Un análisis comparado, (Santiago, Fundación Sol).

ERmida Uriarte, Óscar (2010): "Introducción", en: Cuarenta Estudios sobre la Nueva Legislación Laboral Uruguaya, XXXV aniversario del Grupo de los Miércoles, (Montevideo, Fundación de Cultura Universitaria), pp. 5-12.

(1991): Las relaciones del trabajo en américa latina, (Lima, Crítica \& Comunicación, Oficina Regional de la OIT para América Latina y el Caribe).

FerrarI, Vincenzo (2012): "Gino Giugni e la Teoría del Diritto", en: Giornale di Diritto del Lavoro e di Relazioni Industriali, (№ 134, anno XXXIV, 2), pp. 190-203.

Fita Ortega, Fernando (2014): "Los modelos de negociación colectiva en la Unión Europea", en: La negociación colectiva en Chile, (Irene Rojas coord., Santiago, CENTRASS, Librotecnia), pp. 9-38.

Gamonal C., Sergio (2013): "Las dos almas del derecho del trabajo", en: Revista de Derecho Laboral y Seguridad Social, (Volumen I, № 1), pp. 13-22.

(2011): Derecho Colectivo del Trabajo, (2ª edición revisada y actualizada, Santiago, AbeledoPerrot).

Garl, Pedro y Pérez del Castillo, Matías (2016): Empresas y Sindicatos. Manual Práctico de Derecho Sindical, (tercera edición, Montevideo, Fundación de Cultura Universitaria).

Ghera, Edoardo (2007): "Gino Giugni e il Metodo Giuridico", en: Giornale di Diritto del Lavoro e di Relazioni Industriali, ( $N^{\circ} 114$, anno XXIX, 2), pp. 265-272.

Givgnı, Gino (2015): Diritto Sindacale, (actualizado por Lauralba Bellardi, Pietro Curzio y Vito Leccese, Bari, Cacucci).

(2004): Introducción al estudio de la Autonomía Colectiva, (Traducc. José Luis Monereo Pérez y José Antonio Fernández Avilés, Granada, Comares). (1997): Diritto Sindacale, (Bari, Cacucci). (1989): Lavoro, legge, contratti, (Bolonia, II Mulino). (1983): Derecho Sindical, (Madrid, Ministerio de Trabajo y Seguridad Social).

Grossı, Paolo (2007): "Gino Giugni nella scienza giuridica italiana del Novecento", en: Giornale di Diritto del Lavoro e di Relazioni Industriali, (No 114, anno XXIX, 2), pp. 247-264. 
Guarriello, Fausta (2014): "L'Articolo 19 dello Statuto Revisitato", en: Giornale di Diritto del Lavoro e di Relazioni Industriali, (№ 144, anno XXXVI, 4), pp. 767-781.

IMBERTI, Lucio (2013): “A propósito dell'Articolo 8 della Legge No 148/2011: le deroghe si fanno, ma non si dicono", en: Giornale di Diritto del Lavoro e di Relazioni Industriali, (№ 138, anno XXXV, 2), pp. 255-272.

KaHn-Freund, Otto (1987): Trabajo y Derecho, (Madrid, Ministerio del Trabajo y de la Seguridad Social).

LATTARI, Pasquale (2016): Breviario di Diritto Sindacale, (Roma, Armando Curcio Editore).

LECCESE, Vito (2012): "Il diritto sindacale al tempo della crisi. Intervento eteronomo e profili di legittimità costituzionale", en: Giornale di Diritto del Lavoro e di Relazioni Industriali, (№ 136, anno XXXIV, 4), pp. 479-525.

Loustaunau, Nelson E. (2010a): Consejos de Salarios, (Montevideo, Fundación de Cultura Universitaria).

(2010b): "Principales modificaciones introducidas a la Ley No 10.449 de Consejos de Salarios", en: Cuarenta Estudios sobre la Nueva Legislación Laboral Uruguaya, (XXXV aniversario del Grupo de los Miércoles, Montevideo, Fundación de Cultura Universitaria), pp. 15-21.

Mantero Álvarez, Ricardo (1995): "El Ordenamiento Intersindical y las Fuentes del Derecho del Trabajo", en: Treinta y Seis Estudios sobre las Fuentes del Derecho del Trabajo, (Montevideo, Fundación de Cultura Universitaria), pp. 281-303.

Mantero de San Vicente (2015): Osvaldo, Derecho Sindical, segunda edición actualizada por Rodolfo Becerra y Ariel Nicoliello, (Tomo I, Montevideo, Fundación de Cultura Universitaria).

MARESCA, Arturo (2014): “L'Esigibilità del Contratto Collettivo Nazionale: Enigma od Opportunità Practicabile?", en: Giornale di Diritto del Lavoro e di Relazioni Industriali, (№ 143, anno XXXVI, 3), pp. 563-575.

Mariuccl, Luigi (2011): “Un accordo e una legge contro l'accordo", en: Lavoro e Diritto, (3), pp. 451-465.

(1991): "La lunga marcia verso la riforma della rappresentanza sindacale", en: Un progetto per il diritto del lavoro. I temi di riforma per gli anni novanta nella discussione e nelle proposte della Consulta Giuridica della Cgil, (Roma, Ediesse), pp. 15-57.

Mazzotta, Oronzo (2017): Manuale di Diritto del Lavoro, $5^{\text {a }}$ edición, (Milanofiori Assago, CEDAM). 
Nogler, Luca (1997): Saggio sull' Efficacia Regolativa del Contratto Collettivo, (Padua, CEDAM).

OІт (2015): "La cobertura de la negociación colectiva ha disminuido como consecuencia de la crisis financiera mundial", en: http://www.ilo.org/global/ about-the-ilo/newsroom/news/WCMS_415628/lang--es/index.htm (página consultada el 20 de septiembre de 2017).

Олт (2015). "Trends in collective bargaining coverage: stability, erosion or decline?", en: http://www.ilo.org/wcmsp5/groups/public/---ed_protect/---protrav/--travail/documents/publication/wcms_409422.pdf (página consultada el 20 de septiembre de 2017).

OlivierI, Antonello (2014): “El papel y la eficacia de la negociación colectiva en la regulación de la contratación temporal en Italia después de las recientes reformas laborales", en: Derecho a la Negociación Colectiva. Liber Amicorum, Profesor Antonio Ojeda Avilés (Juan Gorelli Coordinador, Sevilla, Consejo Andaluz de Relaciones Laborales), pp. 345-356.

PallinI, Massimo (2016): "Italia Industrial Relations: Towards a Strongly Decentraliced Collective Bargaining?", en: Comparative Labor Law \& Industrial Policy Journal, (Volumen 38:1), pp. 1-21.

Persiani, Mattía (1991): Diritto Sindacale, 4ª edición, (Padova, Cedam).

PINo, Giovanni (2016): Uno studio su Gino Giugni e il conflitto collettivo, (Turín, Giappichelli).

Plá Rodríguez, Américo (1999): "La Función de la Negociación Colectiva en la Defensa del Derecho del Trabajo", en: Scritti in Onore di Gino Giugni, (Tomo II, Bari, Cacucci), pp. 1497-1510.

(1998): Los Principios del Derecho del Trabajo, (3ª edición actualizada, Buenos Aires, Depalma).

Ramos Álvarez, Óscar Gabriel (2009): Marcos Constitucionales para la Negociación Colectiva. América. Europa Occidental y Asia-Pacífico, (México, Porrúa y Facultad de Derecho UNAM).

Raso Delgue, Juan (2014): "Intervención y Autonomía en la Negociación Colectiva: una reflexión desde el modelo pluralista uruguayo de relaciones laborales", en: Derecho a la Negociación Colectiva. Liber Amicorum Profesor Antonio Ojeda Avilés, (Juan Gorelli Coordinador, Sevilla, Consejo Andaluz de Relaciones Laborales), pp. 419-426.

(1998): "Globalización Económica y Negociación Colectiva", en: Globalización Económica y Negociación Colectiva, (IV Congreso Regional Americano de Derecho del Trabajo y de la Seguridad Social, Santiago, 
Sociedad Chilena de Derecho del Trabajo y de la Seguridad Social), pp. 126-136.

Romagnol, Umberto (2007): "Giugni e la Politica Academica", en: Giornale di Diritto del Lavoro e di Relazioni Industriali, (No 114, anno XXIX, 2), pp. 319-327.

Romeo, Carmelo (2015): Il proceso di 'aziendalizzazione' della contrattazione collettiva: tra prossimità e crisi di rappresentatività sindacale, (Working Paper Centre for the Study of European Labour Law "Massimo D'Antona", IT-254/2015, disponible en: http://csdle.lex.unict.it/workingpapers.aspx).

Rosenbaum Rímolo, Jorge (2010): “Un sistema de negociación colectiva. Comentarios a la Ley No 18.566", en: Cuarenta Estudios sobre la Nueva Legislación Laboral Uruguaya, (XXXV aniversario del Grupo de los Miércoles, Montevideo, Fundación de Cultura Universitaria), pp. 45-68.

Santoro-Passarell, Francesco (1963): Nozioni di Diritto del Lavoro, (Nápoles, Jovene).

Santoro-Passarell, Giuseppe (2015): I/ contratto aziendale in deroga, (Working Paper Centre for the Study of European Labour Law "Massimo D'Antona", IT-254/2015, disponible en: http://csdle.lex.unict.it/workingpapers.aspx).

(2007): Diritto sindacale, (Bari, Editori Laterza).

SCARPONI, Stefania (2016): La dottrina giuslavoralistica italiana di fronte al mutamento delle relazioni sindicali e alla questione della rappresentatività, (Working Paper Centre for the Study of European Labour Law "Massimo D'Antona", IT-295/2016, disponible en: http://csdle.lex.unict.it/workingpapers.aspx).

SCIARRA, Silvana (2013): "The 'Autonomy' of Private Goverments. Building on Italian Labour Law Scholarshic in a Transnational Perspective", en: Normative Patterns and Legal Developments in the Social Dimension of the UE (Editado por Ann Numhauser-Henning y Mia Rönnmar, Oxford, Hart), pp. 65-75.

(2010): "Giugni, the Importance of Comparative Methodology and How Labour Law Developed in Italy: a Story from the Nineteen Sixties", en: Fifteen Years with the Norma Research Programme. Anniversary volume (Editado por Ann Numhauser-Henning y Mia Rönnmar, Lund, Lund University), pp. 117-123.

(2009): "Matrici Culturali e Scuole di Diritto del Lavoro. A propósito di due recenti analisi storiche", en: Diritti e Lavoro Nell'Italia Repubblicana (al cuidado de Gian Guido Balandi y Giovanni Cazzetta, Milán, Giuffré), pp. 247-262. 
Supıot, Alain (1996): Crítica del Derecho del Trabajo, (Madrid, Ministerio del Trabajo y Asuntos Sociales).

Tarello, Giovanni (2002): Teorías e Ideologías en el Derecho Sindical, (Traducc. José Luis Monereo Pérez y José Antonio Fernández Avilés, Granada, Comares).

(1995): "Sobre la Autonomía Colectiva", en: Cultura Jurídica y Política del Derecho, (México, Fondo de Cultura Económica), pp. 361-366.

TOMASSETtı, Paolo (2015): Assetti contrattuali tra neoliberalismo e neocorporativismo, (Working Paper ADAPT, 25 maggio 2015, No 179).

VARDARO, Gaetano (1984): Contrattazione collettiva e sistema giuridico, (Nápoles, Jovene).

Villavicencio Ríos, Alfredo (2014): "Constitución, Estructura y Autonomía Sindical en América Latina: El reino espurio de la ley", en: Derecho a la Negociación Colectiva. Liber Amicorum Profesor Antonio Ojeda Avilés (Juan Gorelli Coordinador, Sevilla, Consejo Andaluz de Relaciones Laborales), pp. 561-567.

Walker Errázuirz, Francisco y Arellano Ortiz, Pablo (2017): Derecho de las Relaciones Laborales, Tomo 2 Derecho Colectivo del Trabajo, (Santiago, Librotecnia).

WedDerburn (1998): "Il Diritto del Lavoro Inglese: Un' Introduzione Comparata", en: I Diritti del Lavoro, (Milán, Giuffrè), pp. 5-57. 